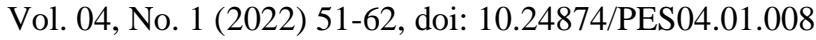 \\ Proceedings on Engineering Sciences
}

\section{SMART VEHICLE IGNITION INTERLOCK: A CAR IGNITION INTERLOCK DEVICE FOR ALCOHOL IMPAIRED DRIVING}

\author{
Benjamin Kommey ${ }^{1}$ \\ Elvis Tamakloe \\ Henry Nunoo-Mensah \\ Daniel Opoku
}

Received 18.11.2021.

Accepted 15.01.2022.

UDC - 614.8.084:629.047

Keywords:

Accident; Alcohol; Breathalyzer; Ignition; Interlock; Impaired driving; Road traffic.

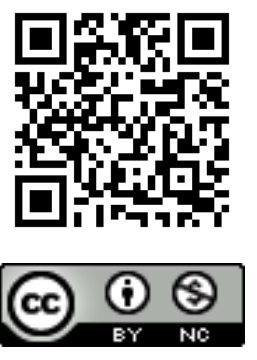

A B S T R A C T

Over the years, road traffic accidents keep claiming lives of people all over the world and alcohol impaired driving is one major cause of these road crashes. While most countries aim at curbing alcohol impaired driving by educating the masses on drunk driving through rallied campaigns, most developed and some developing countries have coupled mass education with technology which includes breathalyzers and ignition interlock devices. This technology has proven to reduce Driving While Intoxicated (DWI) recidivism impressively in countries that have deployed it. This paper aims at proposing a smart vehicle ignition interlock named digiLock to help curb alcohol impaired driving in Ghana and beyond.

(C) 2022 Published by Faculty of Engineering

\section{INTRODUCTION}

Transportation plays a crucial role in every economy simply because it helps in the movement of goods and services. Motor vehicle transportation has proven to be one of the highly patronized modes of transport over the years, and as such accounts for a higher number of transport related fatalities. In the US for instance, transportation-related accidents claimed 39,032 lives in 2017 and 37,133 of those deaths were due to highway crashes (Transportation Statistics Annual Report, 2018). On the average, according to the report, one alcoholimpaired driving fatality occurred every 48 minutes in the United States (Transportation Statistics Annual Report 2018). Ghana recorded 13,877 road accidents involving 22,789 vehicles in 2019 resulting in 2,284 fatalities, the highest fatality figure in the last decade (Road crashes: 2,284 fatalities recorded in 2019 MTTD, 2020). Some major contributing factors to vehicular accidents are alcohol impaired driving, over speeding, inattention of drivers and machine failure. Road accidents often lead to loss of properties, severe injuries, and fatalities in worse case scenarios. Aside from these repercussions on lives and properties, road accidents lead to huge financial loss on the economy.

In Ghana, the National Road Safety Commission estimates an annual loss of over $\$ 230$ million to road accidents (Road crashes: 2,284 fatalities recorded in 2019 - MTTD, 2020). Ignition interlock devices were introduced as means of drastically reducing the rate of alcohol impaired driving in some countries like the US, New Zealand, Netherlands, and Canada. The device

\footnotetext{
${ }^{1}$ Corresponding author: Benjamin Kommey
} 
requires a driver to provide a breath sample for a test, to ensure a driver does not drive under the influence of alcohol. The test is based on the BAC (Blood Alcohol Concentration) level, which is often determined by the country but the standard value being $0.08 \%(80 \mathrm{mg}$ alcohol / 100ml blood). Most of the models introducedhave a wide range of flaws ranging from device tempering, circumventing, long warm up and lockout time. Due to some of these flaws, the implementation of vehicle ignition interlock devices to curb the high rates of alcohol impaired driving on a larger scale, has been gravely affected.

Ghana currently does not implement the use of ignition interlock devices in vehicles, to curb alcohol impaired driving. The only means of checking for alcohol impaired driving in Ghana is the use of breathalyzers by the respective law enforcement agencies at sobriety checkpoints. This alternative is highly inefficient since we do not have enough manpower to test every driver on the road, resulting in more alcohol related accidents. Hence, a need for a more robust and efficient system that addresses the flaws and inconvenience associated with current models, to help reduce the rate of alcohol impaired driving and crashes.

\section{RELATED WORKS}

The surge in road accidents primarily on the negligence of drivers have led to several contributions instituted to remedy this menace to curb and avoid the loss of lives and properties. Aside from the enactment of stringent laws to curb this growing situation, technological advancements have revolutionized to solve the problem of drunk driving or driver under influence (DUI) using interlock devices. Proposals and manufacture of interlock devices come in different methods such as in sensors and AI models. The first performance-based interlock developed by Ignition (2021) has prompted more studies aimed to improve this development.

A few models have been proposed to enable alcohol detection using MQ2 sensors (Rao, n.d.; Prashanth et al., 2014; Surya et al., n.d.; Implementation of advanced safety features in electric cars, n.d.). In this system, the MQ2 sensor samples the breath of the driver, relays the input data to a microcontroller for processing and per the program algorithm based on blood alcohol concentration (BAC) value decisions are made. The processed data either initiates the use of the driving circuitry or locks it according to his or her status. However, this system of alcohol detection is less effective since the sensor generally detects several combustible gases. Hence, has less detection efficiency in certain environments or conditions.

The prototypes presented in (Ms \& Wafgaonkar, 2014; Abiodun et al., 2018; Ahmad et al., 2019; Anthony et al., 2021) employed a less expensive detection system which uses an MQ3 sensor. Like the MQ2 sensor, the
MQ3 sensor has identical operational methods and is mounted closer to the driver to detect the presence of alcohol from expired air. When alcohol is detected, the microcontroller triggers a relay to stop fuel supply or injection which subsequently halts the vehicle. A GSM or Bluetooth module sends information to the subject's next-of-kin or law enforcement agency for immediate action. Though this system increases the efficiency of alcohol detection, it can raise false alarms if a passenger aside the driver is drunk.

A work conducted by Annanouch et al., (2021), Webster \& Gabler (2007) showed a non-invasive technique used to monitor and detect alcohol via skin (finger). This transdermal detection was achieved by using tin dioxide $\left(\mathrm{SnO}_{2}\right)$ chemo-resistive gas sensor. A decline in the resistance of the sensor beyond a particular threshold indicates that the subject is under influence. Additionally, another technique uses a Tru Touch based sensor which employs near-infrared spectroscopy (NIR) to detect alcohol levels (Devi, n.d.; Fu et al., 2012). Based on the information received, an automated lock system is activated. Although simulations were performed to ascertain this concept, fast and early detection was impossible since it takes ample time for alcohol to be biologically detected on skin tissues.

An alcohol detection system for cars through Iris recognition using Gabor filter was presented in (Navarro et al., 2016). The system purposely captures the Iris images of the driver using a CCD camera to detect whether the subject is drunk or not. The captured images are translated as input signals to the microcontroller which controls the car's ignition system through relay circuits. Additionally, detection using pupillometers in alternative methods provide videos of the Iris (Pinheiro et al., 2015). Even though iris recognition gives unique detection and security, more images or videos must be taken to verify the status of the driver. It also does not provide for large scale detection influenced by natural phenomenon like accommodation in the eye due to sudden changes in environment (weather).

Rakshith et al. (2020) present a model that detects alcohol through different channels such as heart rate, alcohol content, facial expression, eye dilation, acceleration, and normal motion of the vehicle. These systems used varieties of sensors to acquire detection. The heartbeat sensor records the heart rate and must be worn for detection. However, this limits the detection to healthy individuals without medical conditions of blood pressure (BP). Though the system provides alternative detection modes, it is not cost effective and raises precision and accuracy concerns.

In the design showcased in (Mal et al., 2014; Marge \& Wang, 2011; Biadsy et al., n.d.; Miller et al., n.d.) are alcohol detection methods using speech recognition. 
These models detected intoxication in speech using Mel-Frequency Cepstral Coefficient (MFCC), phoneticbased kernel system and Convolutional Neural Networks (CNN). Due to differences in dialect, accent and individual inherent speech rate, more training data is required to achieve higher efficiency. This process is therefore cumbersome and highly technical.

Alcohol detection via breathalyzer cannot be overlooked. Varieties of existing breathalyzer techniques are represented in (Tin, 2006; Bihar et al., 2016; Gasparesc, 2018). Expired air suspected to contain alcohol was collected via mouthpiece, passed through vials for analysis and based on the BAC value of the subject, a signal is relayed to the driving circuit from the microcontroller which engages or disengages the ignition system. This system was highly efficient however cannot continuously monitor the driver when the vehicle is in motion.

\section{MATERIALS AND METHODS}

\subsection{DigiLock System Architecture}

Figure 1 gives a visual overview of the digiLock device for alcohol impaired driving. The system consists mainly of a camera unit, a breathalyzer unit, a microcontroller unit, LEDs and an alarm unit.
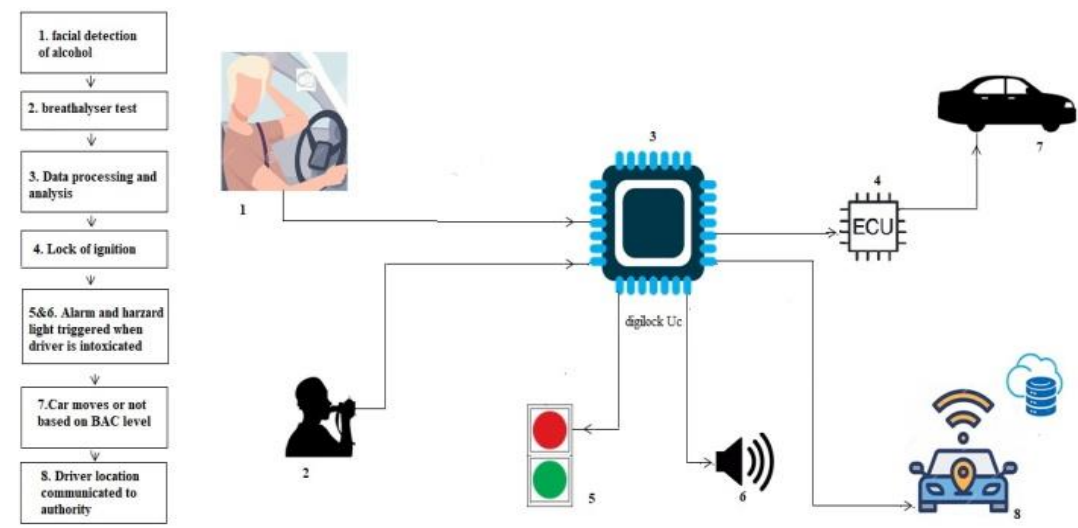

Figure 1. DigiLock System Architecture

When a driver wants to start a car, he first checks his Blood Alcohol Concentration (BAC) using the breathalyzer. The breathalyzer estimates the BAC based on the alcohol in one's breath. Analog signals taken from the breath of the driver via the sensor and sensor module of the breathalyzer are converted to digital word using the microcontroller's ADC. The digital word is fed into the microcontroller for further processing. The signal is analyzed, and the result is communicated to the Engine Control Unit (ECU) of the car. If the analyzed BAC exceeds the set threshold for alcohol, the ignition is not enabled and hence the driver is not able to start the car. Otherwise, the engine is ignited, and the car starts.

While enroute, the IR camera, at regular intervals captures the thermal image of the driver's face and feed same as an input to the microcontroller for processing, The microcontroller unit runs a facial detection algorithm on the input to find face or otherwise. After a face is detected, the thermal data is extracted from the input. Further analysis is carried out on the thermal data to determine if the driver is likely to be intoxicated by indicating a positive or negative result. A positive result will require the driver to take a verification test, using the breathalyzer. If the test result from the microcontroller is positive, it means that either the BAC level of driver exceeds threshold, or the driver has refused to take the verification test. In this case the alarm system unit and hazard light of the car are triggered. The car decelerates slowly till it comes to a standstill or stop. Lastly, the status and location of the driver detected by the Global Positioning System (GPS) module is sent to appropriate authorities using a Global System for Mobile Communication (GSM) module embedded in the system.

\subsection{System Block Diagram}

The digiLock system block diagram as depicted in figure 2, consists of nine sub-blocks: camera, Breathalyzer, communication, indicators, microcontroller, engine control, power, and alarm blocks. The functions of the hardware components shown if figure 2 are explained in table 1.

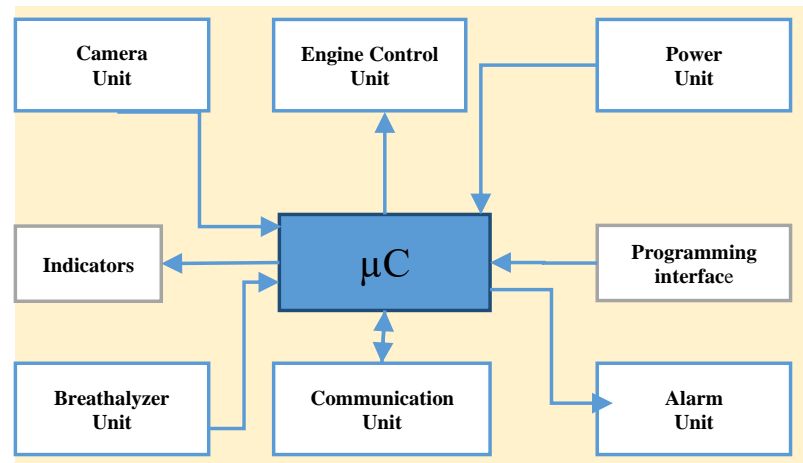

Figure 2. DigiLock System Block Diagram 
Table 1. Hardware Components and functionaldescriptions

\begin{tabular}{|c|l|}
\hline Components & \multicolumn{1}{c|}{ Function } \\
\hline Camera & $\begin{array}{l}\text { An infra-red camera that captures thermal images of the driver's face in the cabin while driving. These images are } \\
\text { transmitted to the microcontroller via a wired connection for processing }\end{array}$ \\
\hline Breathalyzer & $\begin{array}{l}\text { A fuel cell sensor which is used for taking alcohol verification test. The test results are transmitted to the } \\
\text { microcontroller via a wired connection, for processing. }\end{array}$ \\
\hline Indicators & $\begin{array}{l}\text { A few LEDs, which are used for indicating whether a test result is positive or negative. They are used for } \\
\text { indicating the general state of some components within the system. The signals for turning the respective indicator } \\
\text { on }\end{array}$ \\
\hline Communication & $\begin{array}{l}\text { This unit comprises a GSM module and a GPS module. The GPS module determines the live location of the driver } \\
\text { unit } \\
\text { processilst the GSM module is used in transmitting GPS data and additional information about an intoxicated driver, to } \\
\text { the cloud for tracking by law enforcement agencies. }\end{array}$ \\
\hline Engine Control \\
Unit & $\begin{array}{l}\text { This is the car's own control unit, which controls the functioning of major parts of the car, most importantly it } \\
\text { determines whether an ignition should be turned on or off. This unit is connected to the microcontroller through a } \\
\text { wired connection. Based on test results, the microcontroller sends the respective signal to either turn on or off the } \\
\text { ignition. }\end{array}$ \\
\hline Power unit & $\begin{array}{l}\text { This unit comprises the car's battery and a voltage regulator. The car's battery serves as the main source of power } \\
\text { to the entire system while the voltage regulator is used in regulating the output voltage to the respective input } \\
\text { voltage of each component. }\end{array}$ \\
\hline Alarm unit & $\begin{array}{l}\text { This unit comprises the car's hazard light and a buzzer. The unit is connected to the microcontroller through a } \\
\text { wired connection for signal transmission. When an on signal is transmitted, the buzzer beeps to draw the driver's } \\
\text { attention to stop driving while the car's hazard light flashes to draw the attention of the respective road safety } \\
\text { officials who may be on the road. }\end{array}$ \\
\hline
\end{tabular}

\subsection{System Workflow}

The digiLock system's workflow is as shown with a flowchart in figure 3 .

The car's engine is disabled at system start and the driver is made to take an alcohol test using the Breathalyzer. If the results from the test of the
Breathalyzer shows that the driver has an alcohol level greater than the threshold, a buzzer beeps to alert the driver that the test failed indicating the engine cannot start. He or she is to wait for a retest within the next 15 minutes. However, if otherwise the ignition system starts. After the start of ignition, there is another delay of 15 minutes, after which the camera proceeds to capture an image of the driver.

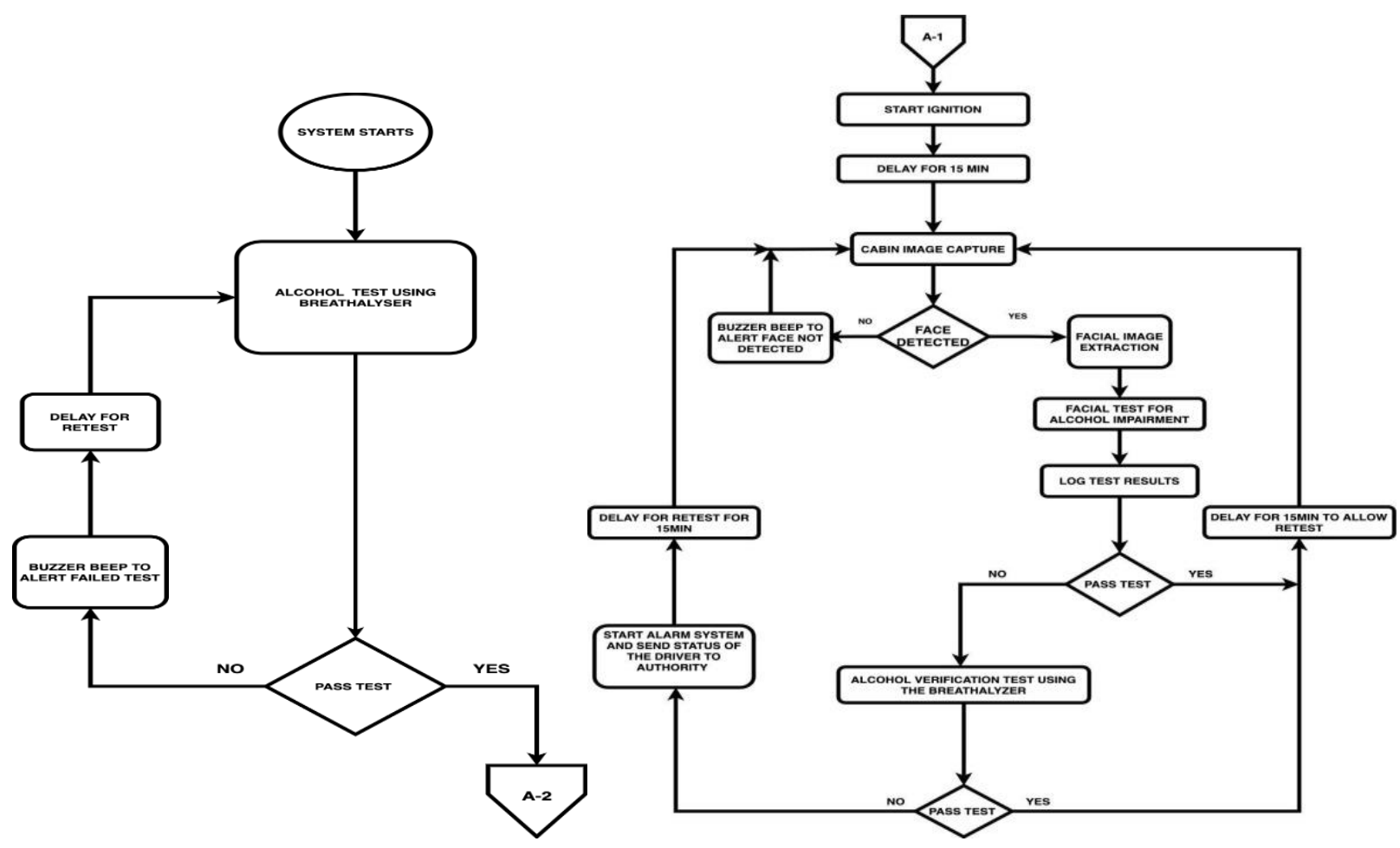

Figure 3. DigiLock System Workflow 
If a face is detected, the system proceeds with the facial image extraction and facial test for impairment. These are all done with the aid of an algorithm running on the microcontroller unit. When the results show any form of intoxication, there is a verification test with the Breathalyzer for confirmation. Whenever the results of the verification test confirm intoxication, the alarm and audio outputs are activated to alert the driver of being intoxicated with alcohol.

Table 2. Prototype Design Components and purposes

\begin{tabular}{|c|c|c|}
\hline Component & Image & Purpose \\
\hline IR Camera & & $\begin{array}{l}\text { Far-infrared thermal sensor array, } 32 \times 24 \text { pixels. Onboard } \\
\text { voltage translator, compatible with } 3.3 \mathrm{~V} / 5 \mathrm{~V} \text { operating } \\
\text { voltage. Communicating via } \mathrm{I} 2 \mathrm{C} \text { interface, configurable } \\
\text { to fast mode }\end{array}$ \\
\hline SDTC Voltage Converter & & $\begin{array}{l}\text { Two-sided panel design with multiple output pins. } \\
\text { Includes } 2 \text { pieces of } 12 \mathrm{~V} \text { to } 3.3 \text { and } 5 \mathrm{~V} \text { voltage converter } \\
\text { module }\end{array}$ \\
\hline Raspberry PI 4 & & $\begin{array}{l}2 \text { USB } 3.0 \text { ports and } 2 \text { USB } 2.0 \text { ports } \\
40 \text { standard GPIO header. Micro-SD card slot for loading } \\
\text { OS. 2-lane MIPI CSI camera port } \\
\text { 2.4 GHz and 5.0 GHz IEEE } 802.11 \mathrm{ac} \\
\text { wireless, Bluetooth 5.0, BLE. OpenGL ES 3.1, Vulkan } \\
1.0\end{array}$ \\
\hline RGB LED & & $\begin{array}{l}2 \mathrm{~V} \text { forward voltage for red pin. } 3.2 \mathrm{~V} \text { forward voltage for } \\
\text { blue and green pins }\end{array}$ \\
\hline GSM MODULE & & $\begin{array}{l}\text { Embedded powerful TCP/IP protocol stack } \\
\text { Quad-band GSM/GPRS module }\end{array}$ \\
\hline Piezo Buzzer & & $\begin{array}{l}\text { Continuous beep sound type } \\
\text { Resonant frequency of } \pm 300 \mathrm{~Hz}\end{array}$ \\
\hline Breathalyzer & & $\begin{array}{l}\text { Response time at } 23^{\circ} \mathrm{C} \text { is } 10 \text { seconds } \\
-40 \text { to } 60{ }^{\circ} \mathrm{C} \text { for storage temperature range } \\
\text { Maximum ethanol concentration of } 300 \mathrm{ug} / 100 \mathrm{ml} \text { air }\end{array}$ \\
\hline GPS Module & $9=$ & $\begin{array}{l}510 \Omega \text { TXD / RXD Impedance. NMEA, UBX Binary, } \\
\text { RTCM communication protocols } \\
4800-230400 \text { serial baud rate }\end{array}$ \\
\hline
\end{tabular}

\subsection{Design Simulation}

The schematic in figure 4 shows the symbols of the four main components used in this project simulation and how they are connected. The individual schematics of the components were developed using the Proteus design and simulation software. The schematics reveal extensively, the various circuitry components of the board and their configuration.

\section{Indicators}

Three LEDs with different colors are used. The red LED is turned on in case of a violation, while a yellow indicates a prompt to take a test and green indicates a passed test.

\section{Alarm unit}

The alarm unit consists of a buzzer which produces sound whenever alcohol is detected. The purpose of the

\subsection{Design Prototyping}

Several design concepts were considered during the plaining stages of the project. Some critical factors that were taken whilst selecting the most suitable design for the project were the issues of cost, power consumption, user friendliness and accuracy of the system. The subsequent section detailed out in table form the preferred set of components considered for both hardware fabrication and the prototype design. voltage translator, compatible with $3.3 \mathrm{~V} / 5 \mathrm{~V}$ operating voltage. Communicating via I $2 \mathrm{C}$ interface, configurable Two-sided panel design with multiple output pins Includes 2 pieces of $12 \mathrm{~V}$ to 3.3 and $5 \mathrm{~V}$ voltage converter module

40 standard GPIO header. Micro-SD card slot for loading OS. 2-lane MIPI CSI camera port

$2.4 \mathrm{GHz}$ and $5.0 \mathrm{GHz}$ IEEE 802.11 ac

wireless, Bluetooth 5.0, BLE. OpenGL ES 3.1, Vulkan

$2 \mathrm{~V}$ forward voltage for red pin. $3.2 \mathrm{~V}$ forward voltage for ue and green pin

Quad-band GSM/GPRS module

Continuous beep sound type

Resonant frequency of $\pm 300 \mathrm{~Hz}$

Response time at $23^{\circ} \mathrm{C}$ is 10 seconds

-40 to $60{ }^{\circ} \mathrm{C}$ for storage temperature range

Maximum ethanol concentration of $300 \mathrm{ug} / 100 \mathrm{ml}$ air

RTCM communication protocols

(800-230400 serial baud rate

buzzer was to create awareness to passengers whenever alcohol is detected. The buzzer is connected to anpn transistor which can supply the buzzer current to switch it on.

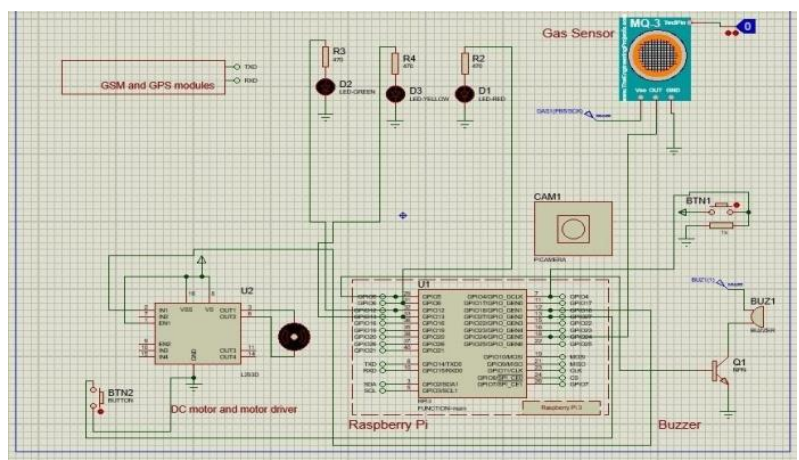

Figure 4. DigiLock Prototype Schematic 


\section{Gas Sensor}

The MQ3 alcohol sensor which is to serve as the breathalyzer unit has four pins. These are the test pin, Vcc, OUT and the GND. The test pin is used to accept logic signals of 0 or 1 by using a logic state pin. When the logic state is 1, it indicates that alcohol is detected above the legal limit and 0 , indicates the absence of alcohol.

\section{Engine Control Unit}

The engine control unit consists of a DC motor, the L293D motor driver, and the push button. The push button here is attached to function as the car key which is used to turn on or off the ignition system of the vehicle. The L293D receives signals from the microprocessor and transmits the relative signal to the dc motor. It has two voltage pins, one which is used to draw current for the working of the L293D and the other is used to apply voltage to the motor. When alcohol is detected, signals from the Raspberry $\mathrm{Pi}$ are used in manipulating the operations of these motors to bring the vehicle to a standstill or stop.

\section{Raspberry PI}

The digiLock system is built around the Raspberry Pi 4 board which has 40 pins on it. The Raspberry pi takes either input or output from the MQ-3 sensor, the pi camera, the push buttons, LEDs, buzzer, DC motor and L293D motor driver as well as the GSM and GPS modules. It performs all the input processing of the system such as turning on or off the LEDs based on the test results from the gas sensor and detecting event changes from the images captured from the camera.

\section{Communication unit}

This unit consists of the GPS and GSM modules. The GPS module determines the live location of the driver whilst the GSM module transmits the GPS data and additional information about the intoxicated driver, to the cloud system used for tracking by law enforcement agencies.

\section{Camera unit}

The Pi camera used in the schematic serves the purpose of capturing images for the detection of event changes. This is based on how bright or dark an image is to check for the probability of intoxication of a driver.

\section{Push buttons}

There are two separate push buttons used in the schematic diagram. BTN1which is connected to GPIO4 acts as a switch to the Raspberry Pi and BTN2 connected to GPIO27 is used to control many operating conditions of the motor, such as start, stop, forward, reverse, fast, and slow.

Figures 5 and 6 show the digiLock system prototype in action

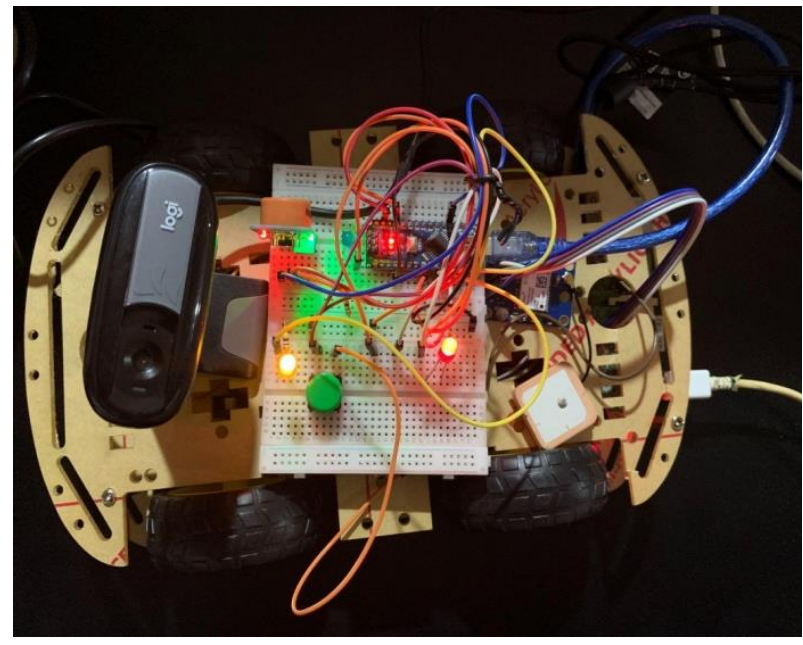

Figure 5. DigiLock Prototype elevated view

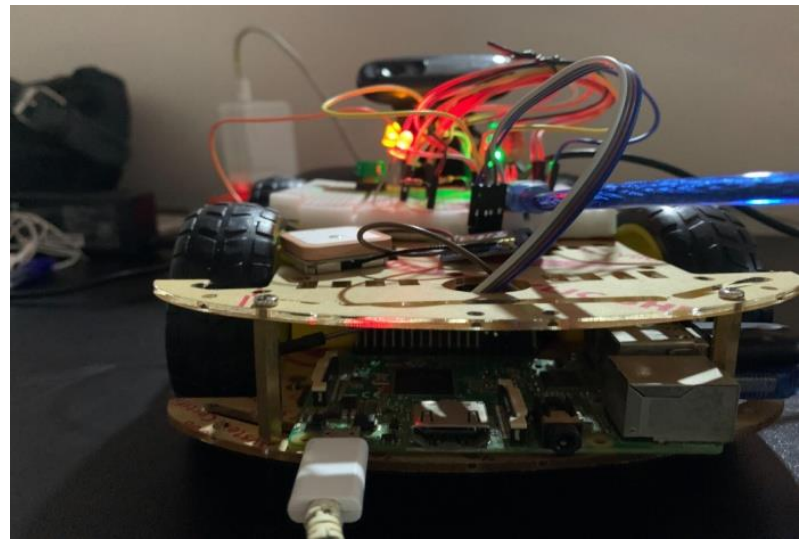

Figure 6. DigiLock Prototype side view

\subsection{DigiLock System Software}

The digiLock system has mainly two software components ie. the embedded software and the webbased user interface software.

\subsubsection{DigiLock Embedded Software}

The chosen programming language for the development of the embedded software is python. This choice was made largely due to the choice of microcontroller which is a raspberry pi. The source code contains the main logic for proper functioning of the system, this is done through signals which are obtained from sensors and computations carried out with respect to the sensor readings. Finally, the corresponding signals are sent to the respective units to carry out actions based on the computation results. The source code works according to the system flow explained in the subsection of the system workflow. The embedded program is scheduled to run as a cron job on the raspberry pi which implies that it automatically begins to run once the digiLock system is powered. 
Table 3. Prototype software test functions

\begin{tabular}{|c|c|}
\hline State & Function \\
\hline Start & $\begin{array}{l}\text { The code is executed immediately the script begins to run. On startup, the script first executes the setup function } \\
\text { which sets the board mode and declares some pin states and ports. The pyfirmata library enables the raspberry pi to } \\
\text { control the Arduino Nano via the USB port.A larger part of the operations and checks are carried out within the btn } \\
\text { function. }\end{array}$ \\
\hline Ignition & $\begin{array}{l}\text { Once the btn function begins execution it initializes some variables which are used in implementing implicit delays } \\
\text { within the system and some other variables. The function continuously checks if the push button which simulates a } \\
\text { car key, has been pressed. Upon detection, an LED is turned on to indicate the system is on, shortly after the user is } \\
\text { prompted using a buzzer and an LED, to undertake an alcohol test before the vehicle will be enabled to move. } \\
\text { Since the ignition is now getting ignited, the user is required to undergo an alcohol test. To ensure the user takes the } \\
\text { test, the system takes reading of the sensor before and after the test has been taken. If the system detects an } \\
\text { appreciable difference between both readings, it proceeds to determine if the driver is intoxicated or not. It returns a } \\
\text { Boolean which determines the car's state as running or stationary. If the driver fails the test, there's an implicit delay } \\
\text { for a specified period and then the process repeats itself until the car's state switches to a TRUE or the ignition is } \\
\text { turned off by pressing the push button. }\end{array}$ \\
\hline En-route & $\begin{array}{l}\text { In simulating a real time check of whether the driver is intoxicated or not, the webcam captures images which are } \\
\text { further analyzed by the check_is_bright() function in the brightImgmodule. This function processes the image } \\
\text { captured and returns a Boolean of TRUE for a bright image and a FALSE for a dark image. A bright image indicates } \\
\text { that a driver is not intoxicated while a dark image suggest that the driver is likely to be intoxicated and therefore will } \\
\text { be required to undertake a test since the car's state will be switched to that of a stationary one. } \\
\text { A conditional check is done to ensure that the vehicle only moves by calling the run_engine() when car_state is } \\
\text { TRUE and the push button has already been pressed. }\end{array}$ \\
\hline test & $\begin{array}{l}\text { This function ensures that the user has taken the test.A comparison between the sensor readings before and after the } \\
\text { test is made. It only proceeds to determine if the test results are positive or negative if it detects an appreciable } \\
\text { difference between the results. If the test results turn out to be positive, the GPS coordinates are read and passed to the } \\
\text { database using the gps_check () and } \boldsymbol{d} \boldsymbol{b}(\text { () functions respectively while the car_state gets set to FALSE. For a negative } \\
\text { test result, the car_state remains TRUE which allows the car to continue moving. In an instance where the test is not } \\
\text { taken, the buzzer is triggered and eventually the car_state is toggled to a FALSE. }\end{array}$ \\
\hline run_eng. & $\begin{array}{l}\text { Function enables the movement of the car by sending signals to the motor driver which cause the DC motors } \\
\text { connected to the car's tyre to begin to move. The function sets the respective pins to which the motor driver is } \\
\text { connected to HIGH. }\end{array}$ \\
\hline stop_eng. & $\begin{array}{l}\text { Function enables the car to remain stationary if there are any violations or the push button has not been pressed to } \\
\text { signify the start of ignition. The function sets the respective pins to which the motor driver is connected to the } \\
\text { microcontroller to LOW }\end{array}$ \\
\hline
\end{tabular}

\subsubsection{DigiLock Web-based Software}

To make the software system efficient such that violators get penalized for their action, a web portal was developed to record activities of drivers. This system allows main administrators to register companies and persons using the devices for personal use. Companies can register their trucks and drivers. Upon violating the system, the location of the driver is taken by the GPS module and rendered on the companies' events page as well as law enforcement agencies' web portal. The law enforcement agencycan login to the system using their credentials to view the location of offenders and to track offenders.

\section{Software Product Functionality}

The web portal would provide services for users with authorization credential. The services to be provided include:

1. Platform for administrators to register users, verify the identity and delete or assign subscriptions

2. Platform for administrators to add drivers and vehicles with the device installed onboard.

3. Finally, it will serve as a platform for law enforcement agencies to view and track violators.
The use case diagrams for the digiLock web-based application software are as shown figure 7 .

\section{TEST AND EVALUATION}

A testing platform was setup to access the functionality of all units individually and collectively. A few testing techniques including some white and black box testing methodologies were used during the test and evaluation.

Following test scenarios where applied:

- a car should remain stationary once the ignition has not been pushed using the push button.

- a car should remain stationary even if the ignition has been pushedbut the driver has either not taken the test or failed.

- a car should come to a standstill whilsten-route when a driver fails a simulated image test for alcohol impairment or verification.

In addition, the system should be able to update a database with user's records and location details whenever there is a violation. These records should also be easily accessible on the digiLock web portal. 


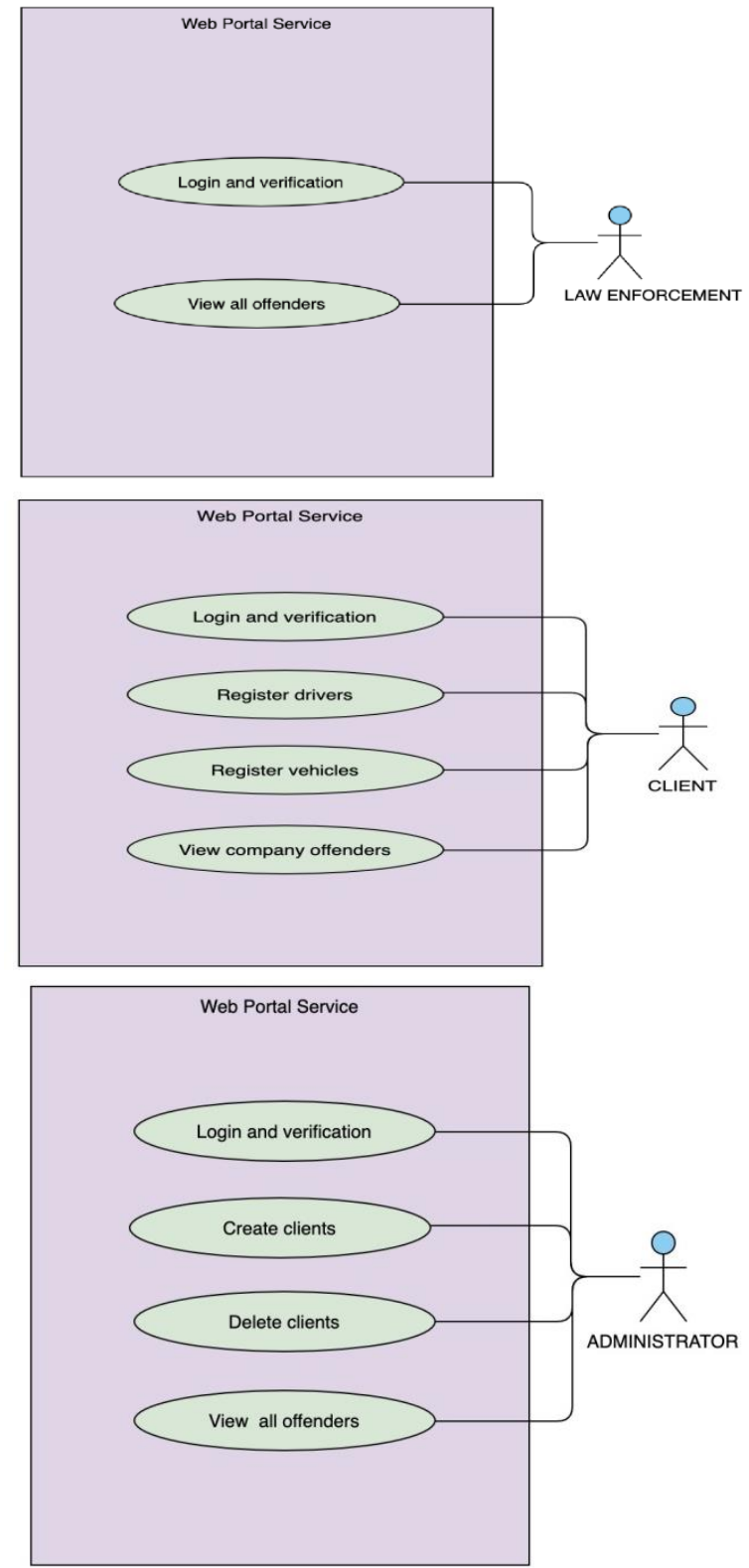

Figure 7. DigiLock Software Use Case Diagrams

The following are some of the case scenarios for the webapplication software:

- Ability for an administrator to login via username and password and be verified.

- Ability for an administrator to create new client accounts for companies.

- Ability for an administrator to create new client accounts for law enforcement.

- Ability for an administrator to view a list of offenders and their respective information within the system.
- Ability for a company client account to login via username and password and be verified.

- Ability for a company client account to register company drivers.

- Ability for a company client account to register company vehicles.

- Ability for a company client account to only view offenders within their company.

- Ability for a law enforcement account to login via username and password and be verified.

- Ability for a law enforcement account to view all offenders within the system.

Test case scenarios for hardware prototype:

- Ability of MQ3 alcohol sensor to effectively measure the quantity of alcohol in a test sample.

- Ability of webcam to capture images at specific intervals.

- Ability of LEDs to light up based on a satisfied condition.

- Ability of GPS module to determine coordinates of driver's current location.

- Ability of the motor driver to control the state of motors based on test results.

- Ability of Arduino nano to convert analog signals to digital signals for further processing by microcontroller.

- Ability of raspberry pi to perform computations on various inputs such as alcohol readings and captured images and deliver preferred outputs based on the test case.

- Ability to turn on or off the system when the push button is pressed.

- Ability to detect when a user fails to take a test.

- Ability to send data to the database when a violation takes place.

\section{Pass / Fail Criteria}

The primary mode of assessment of whether a component or unit functioned properly, was determined from the functions of the major blocks that constitute the system. Once each block or unit is tested, the outcome of the test is compared with expected outcome from that block and based on that, a determination is made, if the block has passed or failed

Figure 8 shows screen shots of the digiLock web-based application's database. 

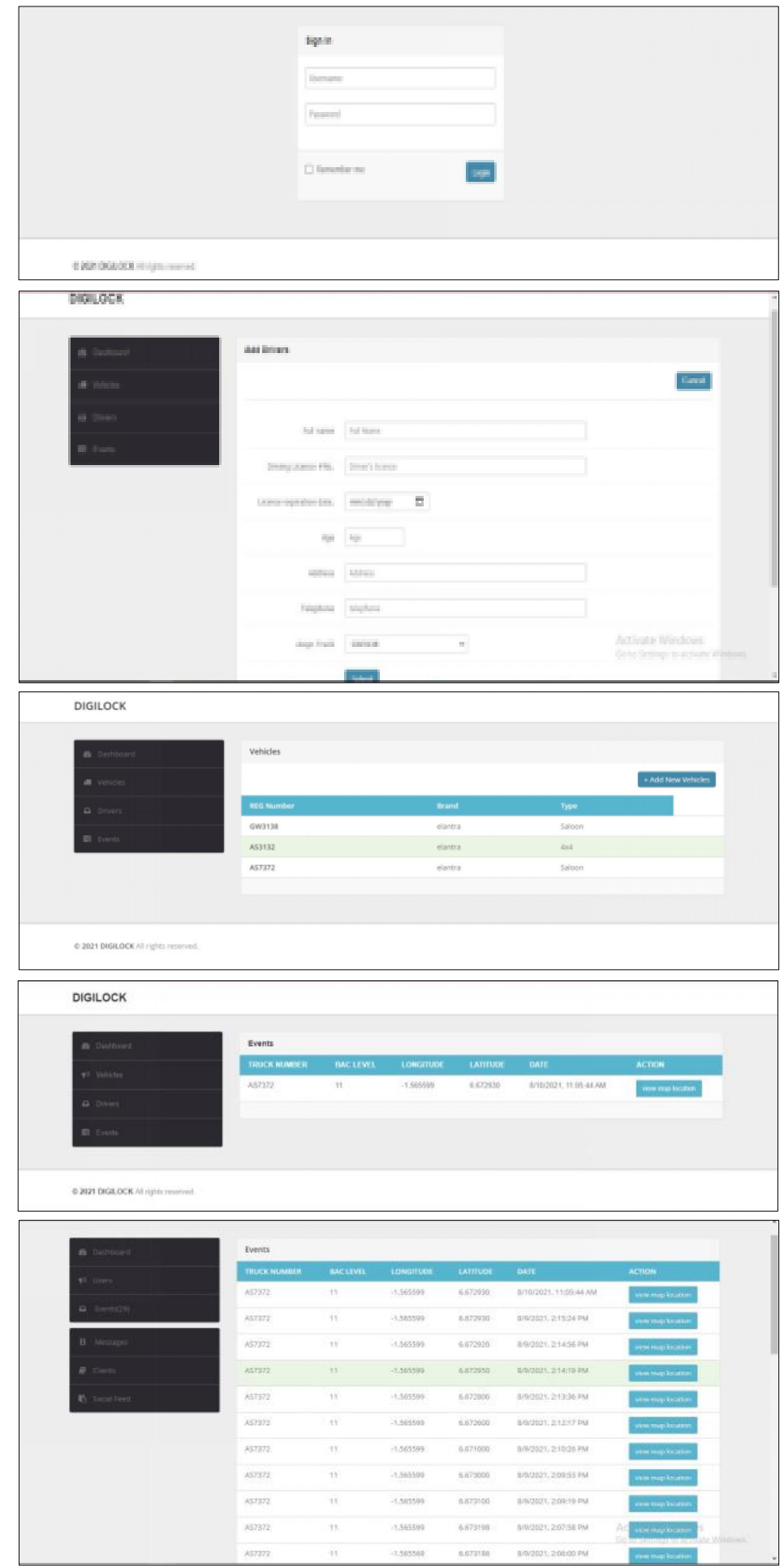

Figure 8. DigiLock Web portal database Results from the test phase of both hardware and software prototypes were collected and analyzed. All units were integrated and tested successfully.

\section{CONCLUSION}

In this paper, a system is proposed to check drunk driving. The system mainly includes a camera unit, a breathalyzer unit, microcontroller unit with GPS and GSM modules. For demonstration purposes, the system is implemented using an MQ-3 sensor with the Raspberry $\mathrm{Pi}$ as the main control unit. The system allows the driver to test for alcohol before ignition starts. If the test turns out to be positive for alcohol, his or her ignition does not start. The system also includes modules that check driver's alcohol level while driving. Upon violating, offenders' information is sent to the right persons and authorities for penalization via the system's web portal. 


\section{References:}

Abiodun, O. M., David, M., \& Audu, W. M. (2018). Alcohol detecting and notification system for controlling drink driving. I-Manager's Journal on Embedded Systems, 7(1), 11. https://doi.org/10.26634/jes.7.1.15658

Ahmad, I., Suhaimi, M. F., \& Yusri, N. A. N. (2019). Development of alcohol sensor detector with engine locking system for accident prevention. Applied physics of condensed matter (APCOM 2019). https://doi.org/10.1063/1.5118204

Annanouch, F. E., Martini, V., Fiorido, T., Lawson, B., Aguir, K., \& Bendahan, M. (2021). Embedded Transdermal Alcohol Detection via a Finger Using SnO2 Gas Sensors. Sensors, 21(20), 6852. https://doi.org/10.3390/s21206852

Anthony, M., Varia, R., Kapadia, A., \& Mukherjee, M. (2021). Alcohol Detection System to Reduce Drunk Driving. International Journal of Engineering Research \& Technology, 9(3). https://www.ijert.org/alcohol-detection-systemto-reduce-drunk-driving

Biadsy, F., Wang, W., Rosenberg, A., \& Hirschberg, J. (n.d.). Intoxication Detection using Phonetic, Phonotactic and Prosodic Cues. Retrieved November 18, 2021, from http://www.cs.columbia.edu/nlp/papers/ 2011/is2011submitted.pdf

Bihar, E., Deng, Y., Miyake, T., Saadaoui, M., Malliaras, G. G., \&Rolandi, M. (2016). A Disposable paper breathalyzer with an alcohol sensing organic electrochemical transistor. Scientific Reports, 6(1), 1-6. https://doi.org/10.1038/srep27582

Devi, S. (n.d.). Alcohol detection using touch based sensors. Retrieved November 18, 2021, from https://www.jetir.org/certificatemanager.php?a_rid=307428

Fu, Q., Wang, J., Lin, G., Suo, H., \& Zhao, C. (2012). Short-Wave Near-Infrared Spectrometer for Alcohol Determination and Temperature Correction. Journal of Analytical Methods in Chemistry, 1-7. https://doi.org/10.1155/2012/728128

Gasparesc, G. (2018). Driver Alcohol Detection System Based on Virtual Instrumentation. IFAC-PapersOnLine, 51(6), 502-507. https://doi.org/10.1016/j.ifacol.2018.07.110

Ignition. (2021). Retrieved February 21, 2021 from https://en.m.wikipedia.org/wiki/Ignition

Kulkarni, P. H., Wafgaonkar, R., Gujarathi, S. S., \& Ahirrao, G. (2014). Alcohol detection and automatic drunken drive avoiding system. Int. Journal of Engineering Research and Applications, 4(4), 21-24. https://core.ac.uk/download/pdf/26990544.pdf

Mal, R., Sharma, R., \& Kumar, N. (2014). Intoxicated Speech Detection using MFCC Feature Extraction and Vector Quantization. International Journal of Electronic and Electrical Engineering, 7(3), $269-280$. https://www.ripublication.com/irph/ijeee_spl/ijeeev7n3_11.pdf

Marge, M., \& Wang, W. (2011). Detecting Intoxication in Speech Researchers at Columbia are investigating ways to automatically detect intoxication in speech. https://www.cs.ucsb.edu/ william/papers/ Detecting_Intoxication_in_Speech.pdf

Miller, J., Donahue, J., \& Schmitz, B. (n.d.). Speech emotion and drunkenness detection using a convolutional neural network. Retrieved November 18, 2021, from http://www2.ece.rochester.edu/ zduan/teaching/ ece477/projects/2018/JoshuaMiller_JillianDonahue_BenjaminSchmitz_ReportFinal.pdf

Navarro, L. A., Diño, M. A., Joson, E., Anacan, R., \& Cruz, R. D. (2016, January). Design of alcohol detection system for car users thru iris recognition pattern using wavelet transform. In 2016 7th International Conference on Intelligent Systems, Modelling and Simulation (ISMS) (pp. 15-19). IEEE.https://doi.org/10.1109/ISMS.2016.60

Pinheiro, H. M., da Costa, R. M., Camilo, E. N. R., da Silva Soares, A., Salvini, R., Laureano, G. T., Soares, F. A., \& Hua, G. (2015). A New Approach to Detect Use of Alcohol Through Iris Videos Using Computer Vision. Image Analysis and Processing — ICIAP 2015, pp. 598-608. https://doi.org/10.1007/978-3-319-23234-8_55

Prashanth, K. P., Padiyar, K., H, Naveen Kumar P. P., \& Kumar, K. S. (2014). Road Accident Avoiding System using Drunken Sensing Technique. International Journal of Engineering Research \& Technology, 3(10). https://www.ijert.org/road-accident-avoiding-system-using-drunken-sensing-technique

Rakshith K. B., Meghana K., Pranav R., Gagana N. A., \& Pavithra G. S. (2020). Alcohol Detection System for the Safety of Automobile Users. International Research Journal of Engineering and Technology, 7(5). https://www.irjet.net/archives/V7/i5/IRJET-V7I5683.pdf

Rao, B. (n.d.). Intelligent alcohol detection system for car. https://www.ijser.org/researchpaper/INTELLIGENTALCOHOL-DETECTION-SYSTEM-FOR-CAR.pdf

Road crashes: 2,284 fatalities recorded in 2019 - MTTD. (2020, January 17). Citinewsroom - Comprehensive News in Ghana. https://citinewsroom.com/2020/01/road-crashes-2284-fatalities-recorded-in-2019-mttd/ 
Surya, G., Swamy, G., Sri, Y., Sai, S., \& Vamsi, A. (n.d.). Detection of Gas and alert by Using Arduino UNO \& MQ2 Sensor. Retrieved November 18, 2021, from https://www.pramanaresearch.org/gallery/prj-p1108.pdf

Transportation Statistics Annual Report 2018 Free Copy Not Meant for Sale. (n.d.). Retrieved November 18, 2021, from https://www.bts.gov/sites/bts.dot.gov/files/docs/browse-statistical-products-and-data/transportation-statisticsannual-reports/TSAR-Full-2018-Web-Final.pdf

Webster, G., \& Gabler, H. C. (2007). Assessment of dermal ethanol emission sensors: experimental design. Biomedical Sciences Instrumentation, 43, 348-353. https://pubmed.ncbi.nlm.nih.gov/17487106/

Win, D. T. (2006). Breath alcohol testers-prevents road accidents. AU Journal of Technology, 10(2), 7580.http://www.thaiscience.info/journals/Article/AUJT/10290623.pdf

\section{Benjamin Kommey}

Kwame Nkrumah University of Science and Technology,

Kumasi,

Ghana

bkommey.coe@knust.edu.gh

\section{Daniel Opoku}

Kwame Nkrumah University of Science and Technology,

Kumasi,

Ghana

do_opokuofficial@yahoo.com

\section{Elvis Tamakloe}

Kwame Nkrumah University of Science and Technology,

Kumasi,

Ghana

tamakloe.elvis@gmail.com

\section{Henry Nunoo-Mensah}

Kwame Nkrumah University of

Science and Technology,

Kumasi,

Ghana

hnmensah@gmail.com 
Kommey et al., Smart vehicle ignition interlock: a car ignition interlock device for alcohol impaired driving 